\title{
Intimate Partner Violence in Older Women
}

\author{
Amy E. Bonomi, PhD, MPH, ${ }^{1}$ Melissa L. Anderson, MS, ${ }^{2}$ \\ Robert J. Reid, MD, PhD, ${ }^{2}$ David Carrell, PhD,${ }^{2}$ Paul A. Fishman, PhD, ${ }^{2}$ \\ Frederick P. Rivara, MD, MPH, ${ }^{3}$ and Robert S. Thompson, $\mathrm{MD}^{2}$
}

Purpose: We describe the prevalence, types, duration, frequency, and severity of intimate partner violence ("partner violence") in older women. Design and Methods: We randomly sampled a total of 370 English-speaking women (65 years of age and older) from a health care system to participate in a crosssectional telephone interview. Using 5 questions from the Behavioral Risk Factor Surveillance System (BRFSS) and 10 questions from the Women's Experience with Battering (WEB) Scale, we assessed a woman's exposure to partner violence. We estimated lifetime partner violence prevalence using the BRFSS questions (physical, forced intercourse, forced sexual contact, verbal threats, and controlling behavior), and we estimated past-5-year and past-year prevalence using the BRFSS and the WEB Scale. We estimated violence frequency, duration, and severity using the BRFSS questions. Results: According to the BRFSS, lifetime partner violence prevalence was $26.5 \% ; 18.4 \%$ of women experienced physical or sexual violence and $21.9 \%$ experienced nonphysical violence (threats or controlling behavior). According to the BRFSS and WEB Scale, past-5-year violence prevalence was $3.5 \%$, and past-year violence prevalence was $2.2 \%$. Many abused women reported more than 20 episodes of violence in their lifetime (from $18.1 \%$ for physical violence to $61.2 \%$ for controlling behavior). The median duration ranged from 3 years (forced sexual contact) to 10 years (controlling behavior). The proportion of abused women rating their abuse as

This research was supported by the Agency for Health Research and Quality. We thank Diana Rowland for assisting with the manuscript preparation and the interviewers from Group Health's Center for Health Studies for telephoning and interviewing the women who participated in the study.

Address correspondence to Amy E. Bonomi, Department of Human Development and Family Science, The Ohio State University, 1787 Neil Avenue, 135 Campbell Hall, Columbus, OH 43214. E-mail: bonomi.1@, osu.edu

${ }^{1}$ Human Development and Family Science, The Ohio State University, Columbus.

${ }^{2}$ Center for Health Studies, Group Health Cooperative, Seattle.

${ }^{3}$ Harborview Injury Prevention \& Research Center and the University of Washington Department of Epidemiology, Seattle. severe ranged from $39.1 \%$ (forced sex or sexual contact) to $70.7 \%$ (threats). Implications: The high lifetime partner violence occurrence, frequency, duration, and severity, coupled with results from prior studies indicating long-term adverse health effects of partner violence, suggest a need for increased efforts to address partner violence in older women.

Key Words: Domestic violence, Intimate partner violence, Prevalence, Assessment, Women

A growing body of research focuses on the prevalence and health impact of intimate partner violence ("partner violence") in women who are aged 65 years or older (Fritsch, Tarima, Caldwell, \& Beaven, 2005; Mouton, 2003; Mouton et al., 2004; Mouton, Rovi, Furniss, \& Lasser, 1999; Pillemer \& Finkelhor, 1988; Podneiks, 1992; Rennison \& Welchans, 2002; Weinbaum et al., 2001). Intimate partner violence is broadly defined by the Centers for Disease Control and Prevention (CDC) as actual or threatened physical or sexual violence used by an intimate partner to cause death, disability, injury, or harm to victims, and psychological abuse used to cause trauma in victims (Saltzman, Fanslow, McMahon, \& Shelley, 1999). Physically violent acts include but are not limited to scratching, shoving, choking, punching, and shaking; sexually violent acts include the use of physical force to compel victims to engage in a sexual act against their will, an attempted or completed sex act by a person who is unable to understand the nature or condition of the act, and abusive sexual contact; and psychological abuse includes acts such as controlling what victims can and cannot do, using verbal put downs, isolating victims, prohibiting access to transportation or the telephone, and inflicting humiliation. The broad definition of partner violence proposed by the CDC is necessary in order to adequately characterize all forms of violence and abuse that could harm victims involved with abusive intimate partners. The growing focus on partner violence in women older than 65 years of age is of particular importance, given the potential for social isolation and functional and 
cognitive impairment in older women (Cohen, Forte, Du Mont, Hyman, \& Romans, 2005) and the tendency for health care providers to think of partner violence as a problem of younger women (Lachs, 2004; Zink, Jacobson, Regan, \& Pabst, 2004).

Published prevalence studies have operationalized the definition of partner violence in numerous ways, contributing to a wide variation in the prevalence estimates of partner violence in older women. Recent studies have estimated a lifetime prevalence of physical assault or psychological abuse (e.g., verbal threats) ranging from $18.1 \%$ in women aged 60 or older who were randomly sampled in the state of Kentucky (Fritsch et al., 2005) to $32 \%$ in women aged 50-79 who participated in the Women's Health Initiative observational study component (Mouton et al., 1999). Past-year physical partner violence rates in women aged 65 years or older ranged from $0.1 \%$ to $0.2 \%$ (Rennison \& Welchans, 2002; Weinbaum et al., 2001). In studies that used broader definitions of partner violence, rates of past-year physical and verbal partner violence were $3.5 \%$ and $21.7 \%$, respectively, in women aged 70-79 (Mouton, 2003).

Some studies that focused on abuse against older adults did not clearly distinguish abuse perpetrated by spouses from abuse perpetrated by significant others (e.g., relatives or other caregivers; see Kurrle, Sadler, \& Cameron, 1992; Lachs, Berkman, Fulmer, \& Horwitz, 1994; Mouton et al., 2004; Ogg \& Bennett, 1992; Podneiks, 1992). In a large random survey of community-dwelling elderly individuals in the Boston metropolitan area, Pillemer and Finkelhor (1988) found that spouses were common perpetrators of abuse against older adults; in $22 \%$ of abuse cases, husbands perpetrated the abuse, and in $36 \%$ of cases, wives perpetrated abuse against husbands.

In spite of promising research describing the prevalence of partner violence in older women, we did not find population-based studies that delineated the prevalence, types, duration, frequency, and severity of partner violence experienced by women in the age group of 65 years and older. In the present investigation, we addressed this information gap. Using 5 questions on physical, sexual, and nonphysical (psychological) violence from the Behavioral Risk Factor Surveillance System (BRFSS) questionnaire (Bensley, Van Eenwyk, \& Wynkoop Simmons, 2003; Harwell \& Spence, 2000; Vest, Catlin, Chen, \& Brownson, 2002) and 10 questions from the Women's Experience with Battering (WEB) Scale (Coker, Pope, Smith, Sanderson, \& Hussey, 2001; Coker, Smith, Bethea, King, \& McKeown, 2000; Smith, Earp, \& DeVellis, 1995), we interviewed 370 women aged 65 years and older by telephone to ascertain partner violence prevalence, types, duration, frequency, and severity. In this article we build on prior analyses of partner violence occurrence and related health effects in 3,429 women aged 18-64 years (Bonomi, Thompson, Anderson, Reid, et al., 2006; Thompson et al., 2006).

\section{Methods}

\section{Setting and Study Sample}

We conducted the study at Group Health Cooperative, a health care system that provides health services to more than 500,000 individuals in western Washington State and northern Idaho. Study procedures were approved by Group Health's Institutional Review Board. We randomly sampled 635 Englishspeaking women aged 65 and older whom we had located through Group Health's automated health plan membership files. We mailed a letter describing the study, and study staff contacted women by telephone to obtain consent to participate in a onetime-only telephone interview. Of 635 women selected, we excluded a total of 55 because of sampling error (5), death (3), severe illness (29), or language or hearing problems (18). Of the 580 remaining women, 178 actively refused participation $(30.6 \%)$. There were 14 passive refusals (women located but not interviewed), and 14 women who could not be located after 20 phone attempts. The response rate was $64.5 \%(374 / 580)$. We excluded an additional 4 women because they reported never having had an intimate partner in their adult lifetime. The final analytic sample comprised 370 women.

Because of the relatively low response rate $(64.5 \%)$, we requested additional approval from Group Health's Human Subjects Committee to access additional automated health plan and clinical data to assess whether there was bias in our results based on the likelihood of response or nonresponse. We created propensity scores using logistic regression to estimate the probability that a subject responded to the survey (Austin, Grootendorst, \& Anderson, 2006; Huang, Frangakis, Dominici, Diette, \& Wu, 2005; Schootman et al., 2006). Our analysis revealed that respondents were slightly younger (75.2 years vs 76.8 years) but enrolled in Group Health for the same length of time $(9.2$ years vs 9.1 years) as nonrespondents. Using adjusted clinical group scores, we found that nonrespondents were more likely to be both nonusers of health care services and very high users of health care services (i.e., at the tail or extreme ends of the health care distribution) in the year prior to administration of the survey. However, overall health status was roughly equal among respondents and nonrespondents (mean adjusted clinical group scores, 3.4 vs 3.3 , respectively). This analysis revealed that nonresponse bias in our sample was negligible and survey responses were representative of women aged 65 and older in the Group Health delivery system.

\section{Data Collection}

The data collected by telephone interview included women's sociodemographic characteristics; 
women's exposure to partner violence in the past year, the past 5 years, and lifetime; and violence duration, frequency, and severity.

Demographic Characteristics, Social Involvement, and General Health. - Women reported information about their age and other socioeconomic indicators, such as education and income. Women also estimated the level of their involvement in voluntary groups or social organizations, from $1=$ very active to $3=$ not active (see Donald \& Ware, 1984; Kawachi, Kennedy, Lochner, \& Prothrow-Stith, 1997; Veenstra, 2000), and their general health, from $1=$ excellent health to $5=$ very poor health, by using a single question from the Short Form-36 Health Survey (Diehr \& Patrick, 2003; Diehr, Patrick, McDonell, \& Fihn, 2003; Ware, Kosinski, \& Dewey, 2000).

\section{Partner Violence Definitions and Exposure} Classification. - Using the Uniform Partner Violence Definitions of the CDC, we defined partner violence as actual or threatened physical and sexual violence used by an intimate partner to cause death, disability, injury, or harm to victims, and psychological abuse used to cause trauma in victims (Saltzman et al., 1999). Intimate partners included spouses, nonmarital partners, former marital partners, and formal nonmarital partners. The CDC has recommended that psychological abuse be considered a type of violence only when there has also been prior actual or threatened physical or sexual violence. Violence prevention experts have included psychological abuse in their operationalization of partner violence. Strauss, a leading violence researcher, includes a sizable psychological violence assessment section in the widely used Conflict Tactics Scale, an instrument used to assess exposure to partner violence (Strauss, Hamby, Boney-McCoy, \& Sugarman, 1996).

In our study, victims included women age 65 and older who were the targets of violence and abuse according to the following definitions: (a) physical violence (being hit, slapped, shoved, choked, kicked, shaken, or otherwise physically hurt by an intimate partner); (b) sexual violence (being forced to have oral, vaginal or anal intercourse or forced to have sexual contact that did not result in intercourse); and (c) psychological (nonphysical) abuse (being afraid as a result of an abusive partner's anger or threats, or being repeatedly put down verbally, called names, or having one's behavior controlled).

We operationalized these dimensions of violence and abuse using five questions from the CDC's BRFSS survey (Bensley et al., 2003; Harwell \& Spence, 2000; Vest et al., 2002), which asked women if they had ever been: hit, slapped, shoved, choked, kicked, shaken, or otherwise physically hurt by an intimate partner (one question); forced to have oral, vaginal or anal intercourse (one question); forced to have sexual contact that did not result in intercourse (one question); feared for their safety because of their partner's anger or threats (one question); or were repeatedly put down, called names, or had their behavior controlled by an intimate partner (one question; see Appendix A). If women reported that any of these abuse types had occurred in their lifetime, they were then asked whether the violence occurred in the past 5 years and in the past year. We considered women who responded affirmatively ("yes") to any of the specific BRFSS abuse types (sexual, physical, threats, or controlling behavior) to be exposed to that abuse type. We considered women to be exposed to sexual abuse if they reported either forced sexual intercourse or forced sexual contact that did not result in intercourse according to the BRFSS questions.

For each of the abuse types in the BRFSS questions (physical, sexual, threats, and controlling behavior), we asked women about the number of abusive partners with whom they had been involved, and the number of abusive episodes they experienced across all partners. We also asked women about the start and end dates of each BRFSS abuse type to estimate the number of years encompassed by partner violence in their adult lifetime. For each BRFSS abuse type (physical, sexual, threats, and controlling behavior), women rated their perceived severity of the abuse they experienced (range, $1=$ not at all violent to $4=$ extremely violent; see McNutt, Carlson, Rose, \& Robinson, 2002).

Because violence researchers have strongly suggested the use of very broad definitions of partner violence to assess abuse exposure (Bonomi, Allen, \& Holt, 2006; Coker et al., 2001), we included a second definition of partner violence that reflected women's underlying fear and loss of power and control in their lives associated with exposure to abuse. To assess this dimension of abuse, we used the WEB Scale (Coker et al., 2000, 2001; Smith et al., 1995; see Appendix A). This scale was developed to measure women's fear, loss of control, and disempowerment as a result of abuse exposure. The WEB Scale is viewed as a less intrusive approach to measure partner violence exposure, because it identifies common feelings associated with being a victim of partner violence (e.g., fear and disempowerment) without requiring women to label themselves as victims (or their partners as perpetrators committing abusive acts toward them; see Bonomi, Thompson, Anderson, Rivara, et al., 2006).

For the WEB Scale administration, study staff members first asked women to name their three most recent adult intimate partners. Women answered the 10 WEB questions for each partner. The WEB Scale response options ranged from 1 (strongly disagree) to 6 (strongly agree). Scores of 20 or higher (range $=$ 10-60) indicated occurrence of abuse (Coker et al., 2001). The reliability of the 10 WEB questions 
(measured by an alpha coefficient) was high across the three partners, with a range from 0.88 for Partner 1 to 0.97 for Partner 3. At the completion of each WEB survey, staff members asked women with WEB scores of 20 or higher to estimate the start and end dates of their abuse to the nearest year. We used these estimates to designate past-year and past-5year abuse exposure according to the WEB Scale. Because the WEB questions were asked for three partners only, we could not estimate lifetime partner violence prevalence using the WEB Scale.

\section{Analytic Methods}

We estimated partner violence frequency in the past year and past 5 years using the WEB and BRFSS questions. We estimated lifetime prevalence of partner violence using the BRFSS questions. We estimated the proportion of women who reported more than one abuse type according to the BRFSS questions. Frequencies and measures of central tendency were used to describe partner violence frequency, duration, and severity for each abuse type (physical, sexual, threats, and controlling behavior) in the BRFSS.

\section{Results}

\section{Characteristics of Women}

Approximately $50 \%$ of women were $65-74$ years of age and $50 \%$ were older than 75 years of age (Table 1). Consistent with Group Health enrollees, most women reported White race $(91.4 \%)$ and residence in urban areas $(84.5 \%)$. Of the women, $84 \%$ reported an annual income of less than $\$ 50,000$, and $67.5 \%$ completed some college. Fifty-five percent of women reported current involvement in an intimate relationship, and $53.3 \%$ were currently married. Finally, $56.6 \%$ of women reported fair or very active involvement in organized social groups and $43.9 \%$ reported very good or excellent health.

\section{Prevalence of Partner Violence}

According to the BRFSS or WEB questions, 2.2\% of women reported any partner violence exposure in the past year, and $3.5 \%$ reported partner violence in the past 5 years (Table 2). Both the BRFSS and the WEB questions identified some women as abused who would have been missed had only one of the instruments been used. Of note, $1.6 \%$ of women reported partner violence in the past year on the WEB but not the BRFSS questions, and 1.9\% reported partner violence in the past 5 years on the WEB but not the BRFSS questions.
Table 1. Characteristics of Women $(N=370)$

\begin{tabular}{|c|c|}
\hline & $n(\%)$ \\
\hline \multicolumn{2}{|l|}{ Age (years) } \\
\hline $65-74$ & $176(47.6)$ \\
\hline $75-84$ & $158(42.7)$ \\
\hline$>85$ & $36(9.7)$ \\
\hline \multicolumn{2}{|l|}{ Race or ethnicity } \\
\hline White & $338(91.4)$ \\
\hline Black & $5(1.4)$ \\
\hline Asian-Pacific Islander & $6(1.6)$ \\
\hline American Indian & $9(2.4)$ \\
\hline Multiracial & $4(1.1)$ \\
\hline Other & $8(2.2)$ \\
\hline \multicolumn{2}{|l|}{ Income $(\$)$} \\
\hline$<25,000$ & $114(35.9)$ \\
\hline $25,000-49,999$ & $153(48.1)$ \\
\hline $50,000-74,999$ & $31(9.8)$ \\
\hline$\geq 75,000$ & $20(6.3)$ \\
\hline \multicolumn{2}{|l|}{ Geographic residence } \\
\hline Urban & $305(84.5)$ \\
\hline Rural & $56(15.5)$ \\
\hline \multicolumn{2}{|l|}{ Education } \\
\hline High school or less & $120(32.5)$ \\
\hline At least some college & $249(67.5)$ \\
\hline \multicolumn{2}{|c|}{ Intimate partner relationship status } \\
\hline In past, but not current & $167(45.1)$ \\
\hline Current & $203(54.9)$ \\
\hline \multicolumn{2}{|l|}{ Marital status } \\
\hline Widowed & $129(35.1)$ \\
\hline Divorced-separated & $43(11.7)$ \\
\hline Married-life partner & $196(53.3)$ \\
\hline \multicolumn{2}{|l|}{ Social involvement } \\
\hline Not active & $160(43.4)$ \\
\hline Fairly or very active & $209(56.6)$ \\
\hline \multicolumn{2}{|l|}{ General health } \\
\hline Excellent & $38(10.3)$ \\
\hline Very good & $124(33.6)$ \\
\hline Good & $132(35.8)$ \\
\hline Fair & $57(15.5)$ \\
\hline Poor & $18(4.9)$ \\
\hline
\end{tabular}

\section{Types of Partner Violence}

Table 3 shows the types of abuse that women reported in the BRFSS questions in the past year, past 5 years, and lifetime. According to the BRFSS, $26.5 \%$ of women reported partner violence of any type (physical, sexual or nonphysical) in their lifetime. Eighteen percent reported physical or sexual partner violence in their adult lifetime, and 21.9\% reported nonphysical (psychological) abuse (threats or controlling behavior).

\section{Overlap Between Partner Violence Types}

Among women with lifetime partner violence exposure, most women reported experiencing more than one type of partner violence (Table 4). For 
Table 2. Prevalence of Intimate Partner Violence

\begin{tabular}{|c|c|c|c|c|}
\hline \multirow[b]{2}{*}{ Prevalence } & \multicolumn{2}{|c|}{ Past Year } & \multicolumn{2}{|c|}{ Past 5 Years } \\
\hline & $n$ & $\begin{array}{c}\text { Prevalence } \\
\quad(\%)\end{array}$ & $n$ & $\begin{array}{l}\text { Prevalence } \\
\quad(\%)\end{array}$ \\
\hline $\begin{array}{l}\text { Any partner violence exposure } \\
\text { Partner violence on the }\end{array}$ & 8 & 2.2 & 13 & 3.5 \\
\hline $\begin{array}{l}\text { BRFSS survey } \\
\text { Partner violence on the }\end{array}$ & 2 & 0.5 & 6 & 1.6 \\
\hline WEB Scale & 7 & 1.9 & 11 & 3.0 \\
\hline Neither & 362 & 97.8 & 357 & 96.5 \\
\hline BRFSS only & 1 & 0.3 & 2 & 0.5 \\
\hline WEB only & 6 & 1.6 & 7 & 1.9 \\
\hline Both & 1 & 0.3 & 4 & 1.1 \\
\hline
\end{tabular}

Notes: BRFSS = Behavioral Risk Factor Surveillance System; WEB = Women's Experience with Battering. For prevalence, any partner violence exposure refers to any such exposure detected by the BRFSS or WEB questions; partner violence on the BRFSS survey refers to physical, sexual (forced intercourse or forced sexual contact), or nonphysical (i.e., psychological violence defined as threats or controlling behavior) partner violence; partner violence on the WEB Scale is defined as having WEB scores $\geq 20$.

example, $68.5 \%$ of abused women who reported experiencing controlling behavior also experienced some other type of abuse. Ninety-five percent of abused women who reported sexual partner violence also had some other abuse exposure type.

\section{Partner Violence Frequency, Duration, and Severity}

Across the BRFSS types, more than $90 \%$ of abused women reported having only one abusive partner in their adult lifetime (Table 5). However, partner violence frequency and duration were high. For example, $18.1 \%$ and $61.2 \%$ of abused women reported experiencing 20 or more episodes of physical violence or controlling behavior, respectively. Median abuse duration ranged from 3 years (forced sexual contact) to 10 years (controlling behavior). A high proportion of women reported physical abuse $(61.3 \%)$ and threats $(70.7 \%)$ as moderately or extremely violent. Nearly $40 \%$ of women $(39.1 \%)$ said the sexual abuse they experienced was moderately or extremely violent.

\section{Discussion}

Older women (65 years of age and older) reported a lifetime partner violence prevalence of $26.5 \%$, with $18.4 \%$ of women having physical or sexual abuse, or both, and $21.9 \%$ having nonphysical abuse (i.e., psychological abuse defined as threats or controlling behavior) as measured by the BRFSS questions. According to the BRFSS and WEB questions, past-5year partner violence prevalence was $3.5 \%$, and pastyear prevalence was $2.2 \%$. Older women reported a lifetime partner violence duration ranging from 3
Table 3. Prevalence of Partner Violence by Type

\begin{tabular}{lccc}
\hline \hline & \multicolumn{2}{c}{ Past Year Past 5 Years } \\
Type & $n(\%)$ & $n(\%)$ & $\begin{array}{c}\text { Lifetime } \\
n(\%)\end{array}$ \\
\hline Any BRFSS & $2(0.5)$ & $6(1.6)$ & $98(26.5)$ \\
$\begin{array}{l}\text { BRFSS: Physical or sexual } \\
\quad \text { partner violence }\end{array}$ & $1(0.3)$ & $4(1.1)$ & $68(18.4)$ \\
$\quad$ Physical & $1(0.3)$ & $4(1.1)$ & $62(16.8)$ \\
$\quad$ Forced sex-sexual contact & $1(0.3)$ & $1(0.3)$ & $23(6.2)$ \\
BRFSS: Nonphysical & & & \\
$\quad$ partner violence & $2(0.5)$ & $5(1.4)$ & $81(21.9)$ \\
$\quad$ Threats & $1(0.3)$ & $3(0.8)$ & $42(11.4)$ \\
$\quad$ Controlling behavior & $2(0.5)$ & $3(0.8)$ & $73(19.7)$ \\
\hline
\end{tabular}

Notes: BRFSS = Behavioral Risk Factor Surveillance System. Any BRFSS refers to physical, sexual (forced intercourse or forced sexual contact), or nonphysical (threats or controlling behavior) partner violence on the BRFSS survey.

years (forced sexual contact) to 10 years (controlling behavior). Abuse frequency ( $18 \%$ to $61 \%$ of older women reported 20 or more abuse episodes) and selfrated severity (especially for physical abuse and threats) were also high.

The lifetime prevalence of partner violence in older women $(26.5 \%)$ was consistent with estimates of physical assault and rape in younger women $(25 \%$; see Tjaden \& Thoennes, 2000) and estimates of physical and sexual abuse and lack of safety with an intimate partner in women aged 59 and older $(22 \%$; see Koziol-McClain et al., 2004). However, this lifetime prevalence is lower than one prior lifetime partner violence estimate of $35.5 \%$ in women aged 50-56 (Jones et al., 1999), and it is higher than one prior estimate of $18.1 \%$ in women randomly sampled from Kentucky (Fritsch et al., 2005). As with any retrospective health risk survey, it is conceivable that older women may not recall or may underestimate abuse they experienced in the distant past. It is also possible that older women may not recall the exact dates of their abuse occurrence, and the frequency and severity of their abuse. For example, there may be a tendency over time to downplay the severity of violence that occurred 20 years ago. However, older women's ratings of the severity of their abuse experiences (Table 5) are similar to the severity ratings reported by 3,429 women aged 18-64 in our parent study (Thompson et al., 2006). In the present investigation, we could not assess the role of cognitive degeneration on older women's responses. However, we did not interview women if they were unable to understand the consent procedures.

The past-year partner violence prevalence estimate of $2.2 \%$ in the present study was higher than previous estimates of $0.2 \%$ in women asked about past-year physical violence (Weinbaum et al., 2001) and $0.8 \%$ in women asked about physical, sexual, and psychological partner violence (Fritsch et al., 2005). This discrepancy may be explained by the inclusion of a broader definition of partner violence in the present 
Table 4. Overlap Between Partner Violence (Abuse) Types

Women With Partner Violence in Lifetime

\begin{tabular}{lccc}
\cline { 2 - 3 } & $n$ & $\begin{array}{c}\text { This Abuse } \\
\text { Type Only } \\
(\%)\end{array}$ & $\begin{array}{c}\text { This and Other } \\
\text { Abuse Types } \\
(\%)\end{array}$ \\
\hline $\begin{array}{l}\text { Physical } \\
\quad \text { Physical violence }\end{array}$ & 62 & 25.8 & 74.2 \\
$\quad \begin{array}{l}\text { Forced sex- } \\
\text { contact }\end{array}$ & 23 & 4.3 & 95.7 \\
$\begin{array}{l}\text { Nonphysical } \\
\quad \begin{array}{l}\text { Threats-anger } \\
\text { Controlling } \\
\quad \text { behavior }\end{array}\end{array}$ & 42 & 7.1 & 92.9 \\
$\begin{array}{l}\text { One type } \\
\text { Multiple types }\end{array}$ & 73 & 31.5 & 68.5 \\
\hline
\end{tabular}

Notes: Partner violence in lifetime is according to the BRFSS questions (physical, sexual, or nonphysical abuse); $n=98$.

investigation, which included dimensions of nonphysical (psychological) abuse captured by the BRFSS questions (threats and put downs, name calling, and chronic controlling behavior) and women's perceived loss of power and control in abusive relationships characterized by the WEB Scale. Mouton (2003) reported past-year physical and verbal partner abuse rates of $3.5 \%$ and $21.7 \%$, respectively, in women aged 70-79 years. Studies in younger women indicate that a substantial proportion of women report nonphysical (psychological) partner violence only as captured by the BRFSS (Bonomi, Thompson, Anderson, Rivara, et al., 2006; Thompson et al., 2006), and a significant proportion of women identified as abused by the WEB questions that were not identified by physical partner violence assessment tools (Coker et al., 2001).

We found that the WEB and BRFSS questions identified some women as abused who would have been missed had only one of the instruments been used. The WEB Scale tended to identify more women as abused in the past year and past 5 years that would have otherwise been missed by the BRFSS. This finding corroborates suggestions from prior studies that more than one measurement tool may be useful for screening women for partner violence (Bonomi, Allen, et al., 2006; Bonomi, Thompson, Anderson, Rivara, et al., 2006; Coker et al., 2001).

Our investigation incorporated design features to minimize bias and answer important questions on the presence, types, duration, frequency, and severity of partner violence in older women. Rather than sampling women presenting for clinical services, we randomly selected women from the enrollment files of a large health care organization. Most of the study sample comprised White and urban older women, all of whom had health care insurance. Because the sample did not include older women outside of the health care system, caution is offered against generalizing the results to
Table 5. Abuse Frequency and Severity for Women With Lifetime Partner Violence on the BRFSS

\begin{tabular}{|c|c|c|c|c|}
\hline & $\begin{array}{c}\text { Physical } \\
n(\%)\end{array}$ & $\begin{array}{c}\text { Forced Sex or } \\
\text { Sexual Contact } \\
n(\%)\end{array}$ & $\begin{array}{l}\text { Threats } \\
n(\%)\end{array}$ & $\begin{array}{c}\text { Controlling } \\
\text { Behavior } \\
n(\%)\end{array}$ \\
\hline \multicolumn{5}{|l|}{ No. of partners } \\
\hline 1 & $56(90.3)$ & $22(100.0)$ & $37(90.2)$ & $67(93.1)$ \\
\hline 2 & $5(8.1)$ & $0(0.0)$ & $3(7.3)$ & $3(4.2)$ \\
\hline$\geq 3$ & $1(1.6)$ & $0(0.0)$ & $1(2.4)$ & $2(2.8)$ \\
\hline \multicolumn{5}{|c|}{ No. of occurrences } \\
\hline Once & $11(18.0)$ & $5(23.8)$ & $5(12.5)$ & $0(0.0)$ \\
\hline Twice & $8(13.1)$ & $1(4.8)$ & $1(2.5)$ & $2(3.0)$ \\
\hline $3-5$ times & $14(23.0)$ & $3(14.3)$ & $10(25.0)$ & $9(13.4)$ \\
\hline 6-10 times & $9(14.8)$ & $4(19.1)$ & $7(17.5)$ & $6(9.0)$ \\
\hline 11-20 times & $8(13.1)$ & $1(4.8)$ & $2(5.0)$ & $9(13.4)$ \\
\hline 20-50 times & $7(11.5)$ & $3(14.3)$ & $9(22.0)$ & $13(19.4)$ \\
\hline$>50$ times & $4(6.6)$ & $4(19.1)$ & $6(15.0)$ & $28(41.8)$ \\
\hline \multicolumn{5}{|c|}{ Abuse duration (years) } \\
\hline Mean (SD) & $9.1(10.2)$ & $7.9(10.2)$ & $11.4(10.7)$ & $14.7(14.3)$ \\
\hline Median & 5.0 & 3.0 & 9.5 & 10.0 \\
\hline \multicolumn{5}{|l|}{ Abuse severity } \\
\hline $\begin{array}{l}\text { Not violent } \\
\text { Slightly }\end{array}$ & $3(4.8)$ & $7(30.4)$ & $1(2.4)$ & $26(35.6)$ \\
\hline violent & $21(33.9)$ & $7(30.4)$ & $11(26.8)$ & $20(27.4)$ \\
\hline Moderately & & & & \\
\hline $\begin{array}{l}\text { violent } \\
\text { Extremely }\end{array}$ & $25(40.3)$ & $7(30.4)$ & $23(56.1)$ & $21(28.8)$ \\
\hline violent & $13(21.0)$ & $2(8.7)$ & $6(14.6)$ & $6(8.2)$ \\
\hline
\end{tabular}

Notes: BRFSS $=$ Behavioral Risk Factor Surveillance System; $S D=$ standard deviation. For physical abuse, $n=62$; for forced sex or sexual contact, $n=23$; for threats, $n=42$; for controlling behavior, $n=73$.

older women in the United States. Furthermore, our study focused exclusively on intimate partners as perpetrators, whereas many other studies of this age group include a wider range of perpetrators of "elder abuse" (Kurrle et al., 1992; Lachs et al., 1994; Mouton et al., 2004; Ogg \& Bennett, 1992; Podneiks, 1992). We therefore caution readers against comparing prevalence estimates from our study to estimates from studies focused on abuse in older women that include a wider range of perpetrator types.

Our prior work confirmed that the response rate of $64.5 \%$ from the present investigation is within the response rate range reported in other telephone-based surveys that assess abuse exposure (Thompson et al., 2006). However, as noted in the Methods section, we used propensity scores to determine whether there was bias in our results based on the likelihood of response or nonresponse (Austin et al., 2006; Huang et al., 2005; Schootman et al., 2006). Our results indicated that respondents were slightly younger but enrolled within Group Health for same length of time as nonrespondents. Nonrespondents and respondents also used health services (as measured by adjusted clinical group software) at comparable rates. Thus, non-response bias was negligible and survey responses were representative of women aged 65 and older in the Group Health delivery system. 
The present investigation reported detailed information on partner violence prevalence, types, duration, frequency, and severity in older women, addressing an important gap in the research literature on the natural history of abuse in older women. Asking women to respond to the WEB Scale for their three most recent partners captured detailed information about partner violence that women experienced recently in their life. When prevalence data from the present investigation are considered in conjunction with the adverse health effects of partner violence (even long after abuse ceases; see Bonomi, Thompson, Anderson, Reid, et al., 2006; Brokaw et al., 2002; Campbell et al., 2002), a picture of the potential health burden for older women emerges. Over the past several years, a solid consensus has emerged on partner violence program and research development in health care settings. A main focus is the development of large prospective studies to delineate the long-term course of abuse on women's lives and mulitfactorial randomized controlled trials of "best practice" interventions (Cohn, Salmon, \& Stobo, 2002; Nelson, Nygren, McInerney, \& Klein, 2004; Wathen \& MacMillan, 2003). As a starting point, clinicians might routinely assess partner violence using questions from the WEB Scale and the BRFSS, or other measurement tools (Bonomi, Allen, et al., 2006), and ensure a comprehensive and compassionate response to women who report abuse in their relationships (Zink et al., 2004).

Of note, only $3 \%$ of women in the present investigation indicated they had been asked by a health care provider about physical or sexual violence by an intimate partner since age 18 . Furthermore, $84 \%$ of women indicated they would have agreed to do the interview had they known in advance what it would be like for them; $11 \%$ were neutral; and $5 \%$ of women disagreed. Prior investigations noted that older women may be reluctant to disclose partner violence to their health care provider, and, when women did disclose, some felt discounted and unsupported (Zink et al., 2004). Improvements in screening and response to women's revelation of abuse are warranted.

Results from this investigation could be used as a starting place for partner violence prevention planning in older women. Clinicians with access to automated health information records could use these automated tools with question branching logic to address partner violence and other sensitive health issues (Thompson \& Krugman, 2001). In conjunction with routinely asking about partner violence, "best practice" protocols must be in place to guide clinicians when women indicate abuse has occurred. McCaw and colleagues (McCaw, Berman, Syme, \& Hunkeler, 2001; McCaw et al., 2002) demonstrated a prototype linking partner violence questioning to clinical services. Future studies that include larger numbers of women should also undertake analyses to examine risk factors for recent (past-year) partner violence in older women, in order to proactively target older women at risk for partner violence.

\section{References}

Austin, P. C., Grootendorst, P., \& Anderson, G. M. (2006). A comparison of the ability of different propensity score models to balance measured variables between treated and untreated subjects: A Monte Carlo study. Statistics in Medicine [May 17, E-Pub ahead of print].

Bensley, L., Van Eenwyk, J., \& Wynkoop Simmons, K. (2003). Childhood family violence history and women's risk for intimate partner violence and poor health. American Journal of Preventive Medicine, 25, 38-44.

Bonomi, A. E., Allen, D. G., \& Holt, V. L. (2006). Conversational silence, coercion, equality: The role of language in influencing who gets identified as abused. Social Science and Medicine, 62, 2258-2266.

Bonomi, A. E., Thompson, R. S., Anderson, M., Rivara, F. P., Holt, V. H., Carrell, D., et al. (2006). Ascertainment of intimate partner violence using two abuse measurement frameworks. Injury Prevention, 12, 121-124.

Bonomi, A. E., Thompson, R. S., Anderson, M. L., Reid, R. J., Dimer, J. A. Carrell, D., et al. (2006). Intimate partner violence and women's physical, mental, and social functioning. American Journal of Preventive Medicine, 30, 458-466.

Brokaw, J., Fullerton-Gleason, L., Olson, L., Crandall, C., McLaughlin, S., \& Sklar, D. (2002). Health status and intimate partner violence: A crosssectional study. Annals of Emergency Medicine, 39, 31-38.

Campbell, J., Jones, A. S., Dienemann, J., Kub, J., Schollenberger, J., O'Campo, P., et al. (2002). Intimate partner violence and physical health consequences. Archives of Internal Medicine, 162, 1157-1163.

Cohen, M. M., Forte, T., Du Mont, J., Hyman, I., \& Romans, S. (2005). Intimate partner violence among Canadian women with activity limitations. Journal of Epidemiology and Community Health, 59, 834-839.

Cohn, F., Salmon, M. E., \& Stobo, J. D. (2002). Confronting chronic neglect: The education and training of health professionals on family violence. Washington, DC: National Academy Press.

Coker, A. L., Pope, B. O., Smith, P. H., Sanderson, M., \& Hussey, J. R. (2001). Assessment of clinical partner violence screening tools. Journal of the American Medical Women's Association, 56, 19-23.

Coker, A. L., Smith, P. H., Bethea, L., King, M. R., \& McKeown, R. E. (2000). Physical health consequences of physical and psychological intimate partner violence. Archives of Family Medicine, 9, 451-457.

Diehr, P., \& Patrick, D. L. (2003). Trajectories of health for older adults over time: Accounting fully for death. Annals of Internal Medicine, $139(5$ Pt 2), 416-420.

Diehr, P., Patrick, D. L., McDonell, M. B., \& Fihn, S. D. (2003). Accounting for deaths in longitudinal studies using the SF-36: The performance of the Physical Component Scale of the Short Form 36-item health survey and the PCTD. Medical Care, 41, 1065-1073.

Donald, C. A., \& Ware, J. E., Jr. (1984). The measurement of social support. Research in Community Mental Health, 4, 334-335.

Fritsch, T. A., Tarima, S. S., Caldwell, G. G., \& Beaven, S. (2005). Intimate partner violence against older women in Kentucky. Journal of the Kentucky Medical Association, 103, 461-463.

Harwell, T. S., \& Spence, M. R. (2000). Population surveillance for physical violence among adult men and women, Montana, 1998. American Journal of Preventive Medicine, 19, 321-324.

Huang, I. C., Frangakis, C., Dominici, F., Diette, G. B., \& Wu, A. W. (2005). Application of a propensity score approach for risk adjustment in profiling multiple physician groups on asthma care. Health Services Research, 40, 253-278.

Jones, A. S., Gielen, A. C., Campbell, J. C., Schollenberger, J., Dienemann, J. A., Kub, J., et al. (1999). Annual and lifetime prevalence of partner abuse in a sample of female HMO enrollees. Women's Health Issues, 9, 295-305.

Kawachi, I., Kennedy, B. P., Lochner, K., \& Prothrow-Stith, D. (1997). Social capital, income, inequality, and mortality. American Journal of Public Health, 87, 1491-1498.

Koziol-McLain, J., Gardiner, J., Batty, P., Rameka, M., Fyfe, E., \& Giddings, L. (2004). Prevalence of intimate partner violence among women presenting to an urban adult and pediatric emergency care department. New Zealand Medical Journal, 117(1206), 1-8.

Kurrle, S. E., Sadler, P. M., \& Cameron, I. D. (1992). Patterns of elder abuse. Medical Journal of Australia, 157, 673-676.

Lachs, M. S. (2004). Screening for family violence: What's an evidence-based doctor to do? Annals of Internal Medicine, 140, 399-400.

Lachs, M. S., Berkman, L., Fulmer, T., \& Horwitz, R. I. (1994). A prospective community-based pilot study of risk factors for the investigation of elder mistreatment. Journal of the American Geriatrics Society, 42, 169-173.

McCaw, B., Bauer, H. M., Berman, W. H., Mooney, L., Holmberg, M., \& Hunkeler, E. (2002). Women referred for on-site domestic violence services in a managed care organization. Women's Health, 35(2-3), 23-40. 
McCaw, B., Berman, W. H., Syme, S. L., \& Hunkeler, E. F. (2001). Beyond screening for domestic violence: A systems model approach in a managed care setting. American Journal of Preventive Medicine, 21, 170-176.

McNutt, L. A., Carlson, B. E., Rose, I. M., \& Robinson, D. A. (2002). Partner violence intervention in the busy primary care environment. American Journal of Preventive Medicine, 22, 84-91.

Mouton, C. P. (2003). Intimate partner violence and health status among older women. Violence Against Women, 9, 1465-1477.

Mouton, C. P., Rodabough, R. J., Rovi, S. L., Hunt, J. L., Talamantes, M. A., Brzyski, R. G., et al. (2004). Prevalence and 3-year incidence of abuse among postmenopausal women. American Journal of Public Health, 94, 605-612.

Mouton, C. P., Rovi, S., Furniss, K., \& Lasser, N. L. (1999). The associations between health and domestic violence in older women: Results of a pilot study. Journal of Women's Health and Gender Based Medicine, 8, 1173-1179.

Nelson, H. D., Nygren, P., McInerney, Y., \& Klein, J. (2004). Screening women and elderly adults for family and intimate partner violence: A review of the evidence for the U. S. Preventive Services Task Force. Annals of Internal Medicine, 140, 387-396.

Ogg, J., \& Bennett, G. (1992). Elder abuse in Britain. British Medical Journal, 305, 998-999.

Pillemer, K., \& Finkelhor, D. (1988). The prevalence of elder abuse: A random sample survey. The Gerontologist, 28, 51-57.

Podneiks, E. (1992). National survey on abuse of the elderly in Canada. Journal of Elder Abuse, 4, 5-58.

Rennison, C. M., \& Welchans, S. (2002). Intimate partner violence: Bureau of Justice Statistics Special Report. Washington, DC: U.S. Department of Justice.

Saltzman, L. E., Fanslow, J. L., McMahon, P., \& Shelley, G. A. (1999). Intimate partner violence surveillance: Uniform definitions and recommended data elements. Version 1.0. Atlanta, GA: National Center for Injury Prevention and Control, Centers for Disease Control and Prevention.

Schootman, M., Andresen, E. M., Wolinsky, F. D., Malmstrom, T. K., Miller, J. P., \& Miller, D. K. (2006). Neighborhood conditions and risk of incident lower-body functional limitations among middle-aged African Americans. American Journal of Epidemiology, 163, 450-458.

Smith, P. H., Earp, J. A., \& DeVellis, R. (1995). Measuring battering: Development of the Women's Experience with Battering (WEB) Scale. Women's Health, 1, 273-288.
Straus, M. A., Hamby, S. L., Boney-McCoy, S., \& Sugarman, D. B. (1996). The revised Conflict Tactics Scale (CTS2): Development and preliminary psychometric data. Journal of Family Issues, 17, 283-316.

Thompson, R. S., Bonomi, A. E., Rivara, F. P., Anderson, M. L., Reid, R. J., Dimer, J. A., et al. (2006). Partner violence: Prevalence, types, and chronicity in adult women. American Journal of Preventive Medicine, 30 , $447-457$.

Thompson, R. S., \& Krugman, R. (2001). Screening mothers for intimate partner abuse at well-baby care visits: The right thing to do. Journal of the American Medical Association, 285, 1628-1630.

Tjaden, P., \& Thoennes, N. (2000). Full report of the prevalence, incidence and consequences of violence against women: Findings from the National Violence Against Women Survey (Report No. NCJ-183781). Washington, DC: U.S. Department of Justice/Centers for Disease Control and Prevention.

Veenstra, G. (2000). Social capital, SES and health: An individual-level analysis. Social Science and Medicine, 50, 619-629.

Vest, J. R., Catlin, T. K., Chen, J. J., \& Brownson, R. C. (2002). Multistate analysis of factors associated with intimate partner violence. American Journal of Preventive Medicine, 22, 156-164.

Ware, J. E., Kosinski, M., \& Dewey, J. E. (2000). How to score version two of the SF-36 health survey. Lincoln, RI: Quality Metric.

Wathen, C. N., \& MacMillan, H. L. (2003). Interventions for violence against women. Journal of the American Medical Association, 289, 589-599.

Weinbaum, Z., Stratton, T. L., Chavez, G., Motylewski-Link, C., Barrera, N., \& Courtney, J. G. (2001). Female victims of intimate partner physical domestic violence (IPP-DV), California 1998. American Journal of Preventive Medicine, 21, 313-319.

Zink, T., Jacobson, C. J., Jr., Regan, S., \& Pabst, S. (2004). Hidden victims: The healthcare needs and experiences of older women in abusive relationships. Journal of Women's Health (Larchmt), 13, 898-908.

Received April 12, 2006

Accepted September 6, 2006

Decision Editor: Linda S. Noelker, PhD

\section{Appendix A}

Intimate Partner Violence Questions

\begin{tabular}{lll}
\hline \hline Measure & No. of Questions & Content
\end{tabular}

WEB Scale $10 \quad$ My partner made me feel unsafe even in my own home.

I felt ashamed of the things my partner did to me.

I tried not to rock the boat because I was afraid of what my partner might do.

I felt like I was programmed to react a certain way.

I felt like my partner kept me a prisoner.

My partner could scare me without laying a hand on me.

I hid the truth from others because I was afraid not to.

I felt owned and controlled by my partner.

My partner made me feel like I had no control over my life.

BRFSS survey $\quad 5$

My partner had a look that went straight through me and terrified me.

Sexual

Has an intimate partner ever forced you to participate in a sex act (e.g., oral, vaginal, or anal penetration) against your will?

Ever threatened, coerced or physically forced you into any sexual contact that did not result in intercourse or penetration?

Physical

Ever hit, slapped, shoved, choked, kicked, shaken, or otherwise physically hurt you?

Nonphysical

Ever been frightened for your safety, or that of your family or friends because of anger or threats of an intimate partner?

Ever put you down, or called you names repeatedly, or controlled your behavior?

Notes: WEB = Women's Experience with Battering; women were asked to name their three most recent adult intimate (heterosexual or homosexual) partners. They answered the WEB questions (with a range from 1, strongly disagree, to 6, strongly agree) for each partner, and about the start and stop times of abuse, in order for us to determine the duration of abuse. BRFSS $=$ Behavioral Risk Factor Surveillance System. For each BRFSS question (yes or no), women were first asked if the abuse occurred ever, and then whether the abuse occurred in the past 5 years and in the past year. 